\title{
Natural Antibrowning Agents against Polyphenol Oxidase Activity in Annona muricata and Musa acuminata
}

\author{
Michelle B. S. Weerawardana, ${ }^{1}$ Gobika Thiripuranathar, ${ }^{2}$ and Priyani A. Paranagama $\mathbb{D}^{1,2}$ \\ ${ }^{1}$ College of Chemical Sciences, Institute of Chemistry Ceylon, Welikada, Rajagiriya 10107, Sri Lanka \\ ${ }^{2}$ Department of Chemistry, University of Kelaniya, Kelaniya, Sri Lanka \\ Correspondence should be addressed to Priyani A. Paranagama; priyani@kln.ac.lk
}

Received 27 October 2019; Accepted 18 March 2020; Published 14 April 2020

Academic Editor: Sevgi Kolaylı

Copyright (c) 2020 Michelle B. S. Weerawardana et al. This is an open access article distributed under the Creative Commons Attribution License, which permits unrestricted use, distribution, and reproduction in any medium, provided the original work is properly cited.

\begin{abstract}
Fresh-cut fruits and vegetables emerge as popular food for consumers in retail markets. However, a loss of millions of dollars yearly to the food industry has been due to discoloration of fruits and vegetables caused by a pronounced reaction called enzymatic browning, which is caused by the activity of the polyphenol oxidase enzyme present in most of the fruits and vegetables. The main objective of this study was to investigate the natural antibrowning effects of the aqueous extract of ginger and essential oil of cinnamon bark on PPO enzymatic activity in Annona muricata (katu anoda) and Musa acuminata (ash plantains), which are considered to be widely consumable by Sri Lankans due to its respective health benefits. The antibrowning activity analyzed using a UV-visible spectrophotometer at a wavelength of $525 \mathrm{~nm}$ showed that cinnamon bark oil of $0.0035 \mathrm{~g} / \mathrm{mL}$ had a \% inhibitory activity of 51.97 percent on PPO activity in Annona muricata and 49.51 percent on PPO activity in Musa acuminata, while the aqueous extract of ginger of $0.091 \mathrm{~g} / \mathrm{mL}$ had a \% inhibitory activity of 60.90 percent on PPO activity in Annona muricata and 48.10 percent on PPO activity in Musa acuminata, respectively. This study shows that cinnamon bark oil and ginger can be used as effective, natural, nontoxic antibrowning agents that can inhibit the activity of the PPO enzyme, thereby preventing the essence and nutritional benefits of fruits and vegetables.
\end{abstract}

\section{Introduction}

Some of the main attributes considered by consumers when making choices of food are flavour, texture, appearance, and nutritional value. The basic attribute considered in evaluation of food quality is the appearance of food which is mainly impacted by coloration. Coloration could be due to certain naturally occurring pigments such as chlorophyll, carotenoids, and anthocyanins, or by pigments resulting from both enzymatic and nonenzymatic reactions [1]. The most important colour reactions which occur in most of the fruits and vegetables are enzymatic browning, which is catalyzed by the oxidoreductase enzyme, polyphenol oxidase (PPO). In the field of food industry, methods to prevent browning is the subject in great deal of research. Enzymatic browning is the main cause of quality loss in fruits and vegetables around the world and majorly in Sri Lanka. Fruits and vegetables around the world have vast number of health benefits for consumers due to their content of antioxidant compounds, vitamins, and fibres. However, in many fruits and vegetables, changes are seen to occur during preparation (fresh-cut fruits) and storage. These changes induce a pronounced loss of the microbiological and antioxidant qualities. Hence, preservation against oxidation in fruits and vegetables during storage and processing has become an increase in priority in the food industry [2]. Hence, it becomes a highlighting factor that enzymatic browning determines the customer acceptability as well.

The control of enzymatic browning therefore lies upon the understanding of mechanism, the properties of the PPO enzyme, and their substrate and inhibitors.

Polyphenol oxidases, first reported in mushrooms by Schoenbein in 1856, are a widespread group of enzymes found in plants, fungi, bacteria, and animals. This enzyme contains copper at their active site. This metal ion enables them to oxidize the phenolic group of an aromatic compound to a reactive group known as quinones, which are 
reactive oxygen molecules [3]. Most of the fruits and vegetables contain many polyphenolic compounds that can act as substrates for PPO's. Chlorogenic acid, caffeic acid, and catechol are all polyphenols found in fruits and vegetables that can be oxidized to quinones by PPO's. Such quinones are very reactive and can react with each other and surrounding proteins to generate black pigments, called melanins. These compounds are highly UV-active, and its absorbance could be monitored at a wavelength of $525 \mathrm{~nm}$. This was the key analysis technique adopted in this study.

This results in occurrence of dark spots in plant tissue, making the fruit or vegetable inedible [1]. A visible example of enzymatic browning in Solanum melongena (elabatu) is shown in Figure 1. The reaction does not happen frequently until oxygen is introduced, which is one of the most important intrinsic factors other than substrate specificity, $\mathrm{pH}$, and temperature.

Many studies have focused on either inhibiting or preventing PPO activity in foods, and various techniques and mechanisms have been developed over the years for the control of these enzyme activities. It was analyzed that most of the synthetic or chemical inhibitors used were toxic molecules which can react with cellular components causing toxicity. Hence, in this research project, the basic review was to develop inhibition of PPO activity using natural inhibitors. Thus, the objective of this study was to investigate and identify the effect of natural antibrowning agents of PPO in order to increase the shelf life of partially processed fruits and vegetables available in the retail market.

\section{Materials and Methods}

2.1. Selected Fruit and Vegetable Used for Analysis of PPO Activity. Annona muricata (katu anoda in Sinhala, custard apple in English) is a commonly used fruit in Sri Lanka due to its wide range of health and medicinal benefits. The tropical plant is characterized as an evergreen and flowering tree that can stand up to 8 meters tall and produces edible fruits [4]. Most parts of the plant are used in traditional medications in treating various diseases and ailments, including inflammation [5],rheumatism [6], diabetes [7], hypertension [8], and parasitic infestation [9]. The seed is extracted and used to fight against worms, while the fruits are used traditionally to cure arthritis and fever. Both the seeds and fruits are also used to treat parasitic infections.

Musa acuminata (alu kesel in Sinhala, ash plantains in English), the wild species of banana, is a plant of the tropical and subtropical regions. All parts of the plant including fruits, peel, pseudostem, corm, flowers, leaves, sap, and roots have found their use in the treatment of many diseases in traditional medicine. The reported pharmacological activities of $M$. acuminata include antioxidant, antidiabetic, immunomodulatory, hypolipidemic, anticancer, and antimicrobial, especially anti-HIV activity [10]. In most of the Asian countries, it is used along with rice in the form of a curry.

2.2. Selected Inhibitors Used for Analysis. Zingiber officinale (inguru in Sinhala, ginger in English) is a rhizome and is one

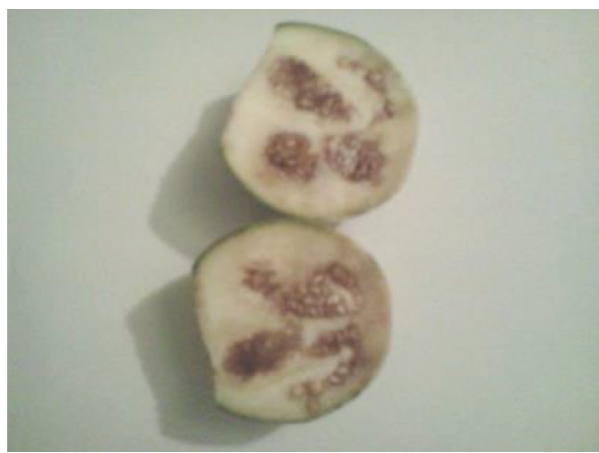

FIgURE 1: Enzymatic browning in Solanum melongena (elabatu). The black coloration shown is a result due to the production of the pigment melanin which is highly UV active.

of the most common spices, which is in use since centuries for its versatile medicinal actions such as antiemetic, stomachic, expectorant, anti-inflammatory, and aphrodisiac in the traditional system of medicine. It is useful for the treatment of various gastrointestinal, pulmonary, cardiovascular, and sexual disorders. The phytochemical study of ginger showed the presence of many volatile oils and oleoresins such as gingerol, zingerone, and zingiberol [11].

Cinnamomum zeylanicum (kurundu in Sinhala, Ceylon cinnamon in English) is a unique and native product in Sri Lanka and in many other Asian countries. The bark and the leaves are widely used. Until now, more than 300 volatiles were found as constituents of essential oils of cinnamon. It has been established that the oils and extracts from cinnamon possess a distinct antioxidant activity, which is especially attributed to the presence of phenolic and polyphenolic substances [12]. Hence, it is used as spices due to its aroma, taste, and colour and as an antioxidant and for many other medicinal purposes [13].

Annona muricata, Musa acuminata, Zingiber officinale, and Cinnamomum zeylanicum were purchased from a retail market in Rathmalana, Sri Lanka.

\subsection{Preparation of Inhibitor Extracts}

2.3.1. Extraction of Essential Oil from Cinnamon Bark. The extraction was carried out by steam distillation of cinnamon bark. Powdered cinnamon bark of $200 \mathrm{~g}$ was added into the collecting flask. The extract obtained after steam distillation contained both oil and water. Hence, a separation was carried out with $\mathrm{CH}_{2} \mathrm{Cl}_{2}$. The oil left over was collected to a sample tube, to which nitrogen gas was passed to remove the remaining $\mathrm{CH}_{2} \mathrm{Cl}_{2}$ from the oil.

2.3.2. Preparation of Ginger (Zingiber officinale) Aqueous Extract. Ginger was peeled and was chopped into cubes (total weight of $100.0 \mathrm{~g}$ ). The mixture was grinded using a pestle and motor. Using cheesecloth, the content was squeezed and the raw extract was obtained. From the raw extract, $5.00 \mathrm{~mL}$ of ginger was taken and topped up to $50.00 \mathrm{~mL}$ in a volumetric flask with deionized water. This solution was then obtained to carry out the analysis. 
2.4. Preparation of Enzyme Extracts from Annona muricata and Musa acuminata. Annona muricata and Musa acuminata were peeled, and $250.0 \mathrm{~g}$ of each of the fruit and vegetable was weighed and homogenized for 1 minute with $500.0 \mathrm{~mL}$ of analytical grade acetone. The homogenates were filtered under gravity filtration using cheesecloth. To the supernatant obtained, $100.0 \mathrm{~mL}$ of phosphate buffer $(0.1 \mathrm{M}, \mathrm{pH} 7)$ was added and stirred on a magnetic stirrer for 10 minutes. Filtration was done using cheesecloth to a stoppered bottle. Filtration was carried out several times until a clear solution was observed (this method declared in [14] was used after modification).

2.5. Analysis of Enzyme-Substrate Activity. An appropriate quantity of the enzyme extract prepared $(50.00 \mathrm{~mL})$ was incubated at a temperature of $35^{\circ} \mathrm{C}$ in a digital water bath for 10 mins. An appropriate amount of substrate $(0.1 \mathrm{M}$ catechol; catecholpyrocatechol assay; GC $98.0 \%, 4.0 \mathrm{~mL}$ ) and phosphate buffer $(0.1 \mathrm{M}, \mathrm{pH} 7.0,6.0 \mathrm{~mL}$ ) were pipetted out into a cuvette (test blank). Into a second cuvette, an appropriate amount of substrate and previously prepared enzyme extracts (incubated at $35^{\circ} \mathrm{C}$ for 10 mins) were added, stoppered, and the solution was mixed and was immediately placed in a spectrophotometer in the sample position. The absorbance was analyzed using the UV/ Vis spectrophotometer (Hitachi- USA U 2910) at a wavelength of $525 \mathrm{~nm}$. The difference in absorbance, between the two solutions, was recorded. These results were duplicated for each test, keeping the overall volume constant [14].

2.6. Analysis of Inhibitory Activity. As measurements are not possible with cinnamon bark oil, $0.5 \mu \mathrm{l}$ of oil was mixed with $0.5 \mu \mathrm{l}$ of Triton X-100 emulsifier. Therefore, a total volume of $0.10 \mathrm{~mL}$ of cinnamon bark oil was used in the study. As done above in Section 2.5, a particular amount of substrate (0.1 M catechol; catechol-pyrocatechol assay; GC 98.0\%, $4.0 \mathrm{~mL})$, phosphate buffer $(0.1 \mathrm{M} \mathrm{pH} 7.0,5.90 \mathrm{~mL})$, and inhibitor extract $(0.10 \mathrm{~mL}$ of cinnamon bark oil and $0.10 \mathrm{~mL}$ of aqueous ginger extract separately) were pipetted out into a cuvette (test blank). Similarly, particular amounts of substrate $0.1 \mathrm{M}$ catechol; (catechol-pyrocatechol assay; GC $98.0 \%, 4.0 \mathrm{~mL})$, inhibitor extract $(0.10 \mathrm{~mL}$ of cinnamon bark oil and $0.10 \mathrm{~mL}$ of aqueous ginger extract separately), and enzyme extract were pipetted out and was placed in the sample position in the meter. The difference in absorption of the two solutions was measured at the same wavelength as above and observed. The experiment was duplicated [14].

On having gathered the absorbance for each inhibitor, the percentage inhibition (I\%) was determined using equation (1) as follows [15]:

$$
I \%=\frac{A_{\mathrm{ES}}-A_{\mathrm{EI}}}{A_{\mathrm{ES}}} \times 100 \%,
$$

where $A_{\mathrm{ES}}$ is the absorbance of enzyme-substrate activity and $A_{\mathrm{EI}}$ is the absorbance of enzyme-inhibitor activity.

\section{Results and Discussion}

3.1. Analysis of Inhibitory Activity of Cinnamon Bark Oil.
Previous results obtained from Journal of Agricultural and Food Chemistry state that on a research carried out on the supercritical $\mathrm{CO}_{2}$ extract of Cinnamomum zeylanicum: chemical characterization and antityrosinase activity, cinnamon bark oil consists $70-75 \%$ of cinnamaldehyde as one of its major constituents and that it shows an inhibition of $40 \%$ on activity of PPO present in white mushrooms (Agaricus bisporus) [16]. On analysis of its inhibitory activity, it could be seen that the compound possess a noncompetitive inhibitory behaviour [16].

Noncompetitive inhibition also known as allosteric inhibition is much defined, where the inhibitor and the substrate can bind simultaneously to an enzyme molecule at different binding sites. Hence, this act of the inhibitory molecule thereby causes a morphological change in the active site which decreases the turnover number rather than diminishing the proportion of substrate molecules that can bind to the enzyme. There seem to be clear evidence that cinnamon bark oil indeed is an inhibitor towards PPO activity.

Additionally, based on preliminary run performed in this study, Tables 1 and 2 report the analytical results concerning the samples prepared.

On overview of these results as shown in Figure 2, it clearly proves that $0.1 \mu \mathrm{l}$ of $0.0035 \mathrm{~g} / \mathrm{mL}$ of cinnamon bark oil caused $51.97 \%$ inhibition of PPO activity in the katu anoda extract and $49.51 \%$ inhibition in the ash plantain extract at $\mathrm{pH}$ 7.0. Therefore, it can be identified that $51.97 \%$ and $49.51 \%$ of inhibition are mainly due to cinnamaldehyde and eugenol present in cinnamon bark oil.

3.2. Analysis of Inhibitory Activity of Ginger. Based on a research carried out on characterization of PPO activity in ginger (Zingiber officinale $R$ ) reports that in rhizomes of different ginger accessions studied, three isoforms, though varied in level of expression, were detected during early and middle stages of rhizome development, whereas a single, predominantly expressed, common isoform was observed at the harvest stage [17].

According to a study carried out on the benefit uses of ginger in herbal preparation, it states that being a rhizome, it consists of 477 different constituents, which include the well-known ascorbic acid, caffeic acid, beta-carotene, curcumin, beta-sitosterol, and limonene. Hence, the analysis with ginger as an inhibitor, in this research, was only to determine whether it possesses any inhibitory activity. The chemistry behind its inhibitory activity is unknown.

This is because even if it shows an inhibitory activity, the chemical constituent responsible for this effect would be a longer research finding as it consists of vast number of chemical constituents [18]. The reaction in Figure 3 thus depicts a possible outcome of the inhibitory activity of ginger due to its well-known constituent, ascorbic acid. The inhibitory activities of ginger on PPO activity of Annona muricata extract and Musa acuminata extract are reported in Tables 3 and 4, respectively. 
TABLE 1: Inhibitory activity of cinnamon bark oil on PPO activity of the Annona muricata extract.

\begin{tabular}{lccr}
\hline & \multicolumn{2}{c}{ Absorbance $(\mathrm{nm})$} & Mean absorbance \\
& $1^{\text {st }}$ absorbance & $2^{\text {nd }}$ absorbance & I\% \\
\hline Enzyme-substrate activity & 0.252 & 0.255 & 0.254 \\
Enzyme-inhibitor activity & 0.125 & 0.119 & 0.122 \\
\hline
\end{tabular}

TABLE 2: Inhibitory activity of cinnamon bark oil on PPO activity of the Musa acuminata extract.

\begin{tabular}{lccr}
\hline & \multicolumn{2}{c}{ Absorbance (nm) } & Mean absorbance \\
& 1st absorbance & 2nd absorbance & I\% \\
\hline Enzyme-substrate activity & 0.210 & 0.198 & 0.204 \\
Enzyme-inhibitor activity & 0.105 & 0.100 & 0.103 \\
\hline
\end{tabular}

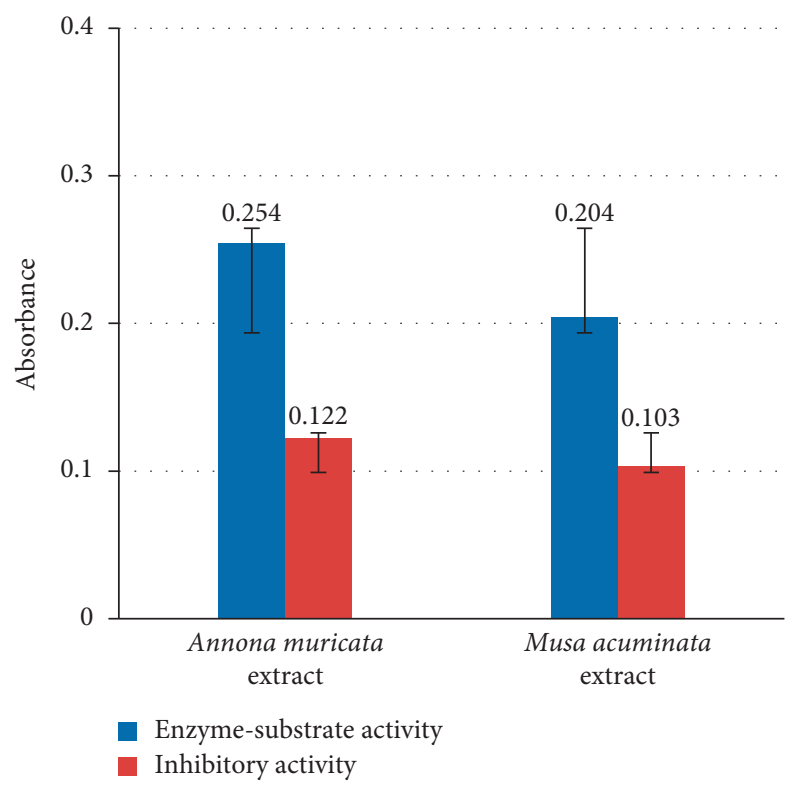

Figure 2: Enzymatic activities and variation of inhibitory activities with cinnamon bark oil.

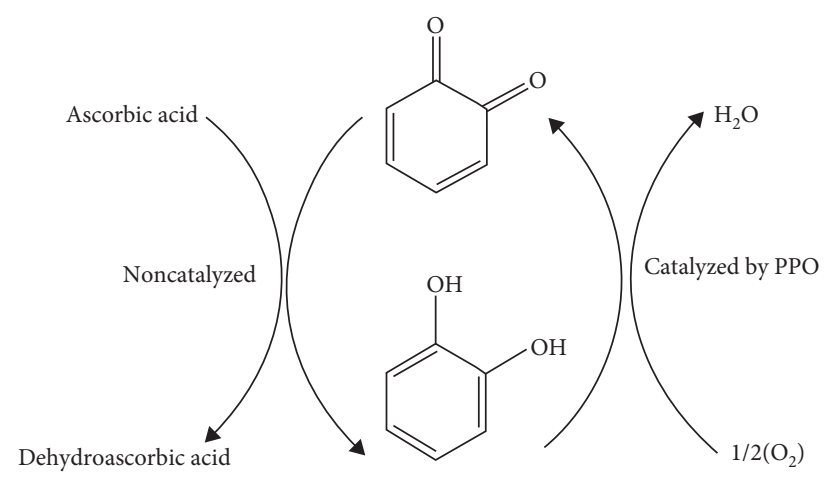

FIGURE 3: Reduction of o-quinones to o-diphenol by ascorbic acid [1].

TABLE 3: Inhibitory activity of ginger on PPO activity of the Annona muricata extract.

\begin{tabular}{lccr}
\hline & \multicolumn{2}{c}{ Absorbance $(\mathrm{nm})$} & Mean absorbance \\
& 1st absorbance & 2nd absorbance & I\% \\
\hline Enzyme-substrate activity & 0.320 & 0.350 & 0.335 \\
Enzyme-inhibitor activity & 0.131 & 0.130 & 0.131 \\
\hline
\end{tabular}


TABLE 4: Inhibitory activity of ginger on PPO activity of the Musa acuminata extract.

\begin{tabular}{lcccc}
\hline & \multicolumn{3}{c}{ Absorbance $(\mathrm{nm})$} & Mean \\
$1^{\text {st }}$ & $\begin{array}{c}2^{\text {nd }} \\
\text { absorbance }\end{array}$ & $\begin{array}{c}\text { absorbance } \\
\text { absorbance }\end{array}$ & $(\%)$ \\
\hline $\begin{array}{l}\text { Enzyme- } \\
\text { substrate } \\
\text { activity }\end{array}$ & 0.212 & 0.208 & 0.210 & \\
$\begin{array}{l}\text { Enzyme- } \\
\text { inhibitor } \\
\text { activity }\end{array}$ & 0.110 & 0.107 & 0.109 & 48.10 \\
\hline
\end{tabular}

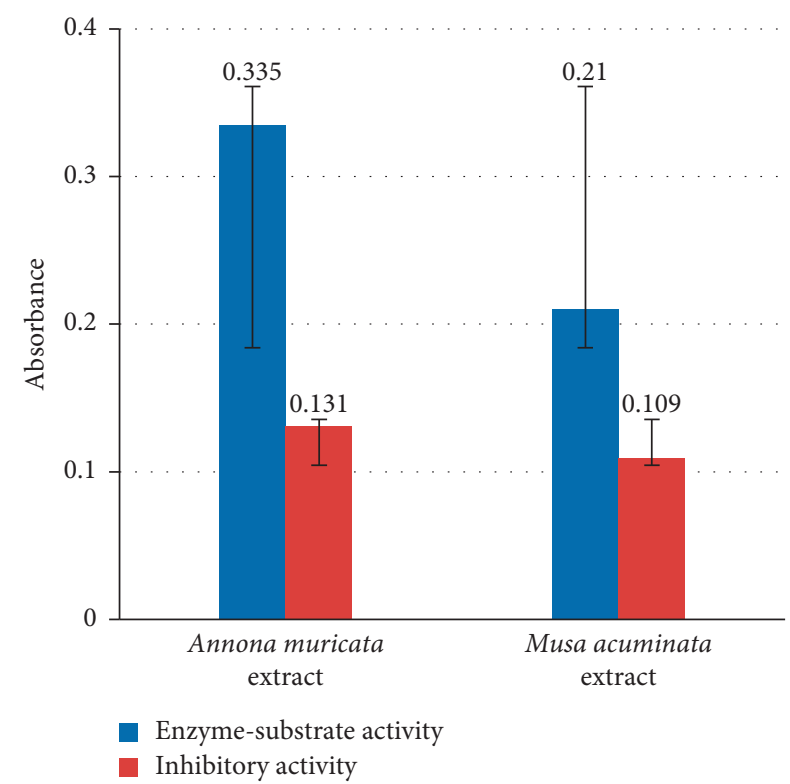

FIGURE 4: Enzymatic activities and variation of inhibitory activities with ginger.

On review of results gathered as shown in Figure 4, we see that it had been an effective inhibitor towards the katu anoda extract with a percentage inhibition of $60.90 \%$ and $48.10 \%$ inhibition for the ash plantain extract, respectively. These results thus infer that ginger indeed shows an inhibitory activity towards PPO, apart from itself being a basic source of PPO.

\section{Conclusion}

The results gathered in this study indicate that inhibition of polyphenol oxidase (PPO) could be carried out in selected fruits and vegetables, katu anoda and ash plantains, which are common to Sri Lanka using natural inhibitors. The experimental findings confirmed the inhibitory effect of cinnamon bark oil and ginger on browning. In addition, the experimental findings suggested that the inhibitory effect of the selected inhibitors varied when experimented upon different enzymatic extracts. Thus, based on results gathered, for katu anoda, the effective inhibitor was ginger, while for ash plantains, Ceylon cinnamon bark oil. Thus, the results conclude that this research study enabled to meet the objectives with positive results on higher percentage inhibitions for browning using natural inhibitors.

\section{Data Availability}

The data used to support the findings of this study are available from the corresponding author upon request.

\section{Additional Points}

In the field of food industry, methods to prevent browning is the subject in great deal of research. Most of these fruits and vegetables available in markets are termed as "ready to cook samples," but in order to preserve them from this unfavorable enzymatic browning reaction, currently a large number of synthetic inhibitors are used, which could seem to have bad effects on consumers and also do generate cost factor. Hence, it becomes a highlighting factor that enzymatic browning determines the customer acceptability as well. Thus, the following research provides a subsidiary method of generating antibrowning agents, which has no bad effect to consumers, and further research could enable to generate a method which is of much lower cost.

\section{Conflicts of Interest}

The authors declare that there are no conflicts of interest regarding the publication of this paper.

\section{Acknowledgments}

Financial support was provided by the College of Chemical Sciences, Institute of Chemistry Ceylon, Rajagiriya, Sri Lanka.

\section{References}

[1] M. R. Marshall, J. Kim, and C. I. Wei, Enzymatic Browning in Fruits, Vegetables and Seafoods, Vol. 5, University of Florida, Gainesville, FL, USA, 2000.

[2] I. Ioannou and M. Ghoul, "Prevention of enzymatic browning in fruit and vegetables," Europian Scientific Journal, vol. 9, pp. 310-341, 2013.

[3] F. Crumière, Inhibition of EnzymaticBrowning in Food Products using Bio-Ingredients, Vol. 104, Mc Gill University, Montreal, Canada, 2000.

[4] R. R. Da Silva, "Enhanced extraction and yields and mobile phase separation by solvent mixtures for the analysis of metabolites in Annona muricata L. Leaves," Journal of Separation Sciences, vol. 32, pp. 4176-4185, 2009.

[5] R. A. Hamid, C. P. Foong, Z. Ahmad, and M. K. Hussain, "Antinociceptive and anti-ulcerogenic activities of the ethanolic extract of Annona muricata leaf," Revista Brasileira de Farmacognosia, vol. 22, no. 3, pp. 630-641, 2012.

[6] S. Mishra, S. Ahmad, N. Kumar, and B. Sharma, "Annona muricata (the cancer killer): a review," Global Pharmaceutical Research Journal, vol. 2, no. 1, pp. 1613-1618, 2013.

[7] S. Z. Moghadamtousi, M. Fadaeinasab, S. Nikzad, G. Mohan, H. M. Ali, and H. A. Kadir, "Annona muricata (Annonaceae): a review of its traditional uses, isolated acetogenins and biological activities," International Journal of Molecular Sciences, vol. 16, no. 7, pp. 15625-15658, 2015.

[8] D. E. Brussell, "A medicinal plant collection from Montserrat, West Indies,” Economic Botany, vol. 58, pp. S203-S220, 2014. 
[9] C. Kamaraj and A. A. Rahuman, "Efficacy of anthelmintic properties of medicinal plant extracts against Haemonchus contortus," Res Vet Sci, vol. 91, no. 3, pp. 400-404, 2011.

[10] N. S. Mathew and P. S. Negi, "Traditional uses, phytochemistry and pharmacology of wild banana (Musa acuminata Colla)," A Review-Journal of Ethnopharmacology, vol. 196, pp. 124-140, 2017.

[11] S. Imtiyaz, K. Rahman, A. Sultana, M. Tariq, and S. S. Chaudhary, "Zingiber officinale Rosc.: a traditional herb with medicinal properties," Tang (Humanitas Medicine), vol. 3, no. 1, 2013.

[12] E. Schmidt, L. Jirovetz, G. Buchbauer et al., "Composition and antioxidant activities of the essential oil of cinnamon (Cinnamomum zeylanicum Blume) leaves from Sri Lanka," Journal of essential oil-bearing plants JEO, vol. 9, no. 2, pp. 170-182, 2008.

[13] Welcome to Cinnamon Vogue, Your Only Source for Real Ceylon Cinnamon (True Cinnamon) or Cinnamomum Zeylanicum (Cinnamon Verum) to Use Its Scientific Names, 2014.

[14] H. A. Mercimek, G. Guzeldag, F. Ucan, K. C. Guler, M. Karaman, and R. Karayilan, "Inhibition of polyphenol oxidase purified from potato (Solanum tuberosum)," Romanian Biotechnological Letters, vol. 20, p. 6, 2015.

[15] S. S. Nair, V. Kavrekar, A. Mishra, C. M. Nithyakala, and B. V. Somashekharaiah, "Investigation of inhibitory activity of selected plant extracts on tyrosinase extracted from Solanum tuberosum," Advanced Biotech Products, vol. 12, no. 15, 2013.

[16] B. Marongiu, A. Piras, S. Porcedda et al., "super critical $\mathrm{CO}_{2}$ extract of Cinnamomum zeylanicum: chemical characterization and antityrosinase activity," Journal of Agricultural and Food Chemistry, vol. 55, pp. 10022-10027, 2007.

[17] A. Joseph, B. Thayumanavan, and P. R. Panicker, "Characterization of polyphenol oxidase in ginger (Zingiber officinale R.)," Journal of Spices and Aromatic Crops, vol. 21, no. 1, pp. 33-41, 2012.

[18] M. Whitney, "Ginger-the benefits of the use of ginger in herbal preparations-chemical constituents of ginger," in The School of Natural Healing-Centennial Edition, Christopher Publications, Springville, UT USA, 2009. 